\title{
Laboreal
}

Volume $9 \mathrm{~N}^{\circ} 1$ | 2013

Varia

\section{Carga mental}

Carga mental

Charge mentale

Mental workload

\section{Carlos Díaz Canepa}

Tradutor. Marta Santos e Marianne Lacomblez

\section{OpenEdition}

\section{Journals}

\section{Edição electrónica}

URL: http://journals.openedition.org/laboreal/6330

DOI: 10.4000/laboreal.6330

ISSN: 1646-5237

\section{Editora}

Universidade do Porto

\section{Refêrencia eletrónica}

Carlos Díaz Canepa, «Carga mental », Laboreal [Online], Volume 9 Nº1 | 2013, posto online no dia 01 julho 2013, consultado o 15 setembro 2020. URL : http://journals.openedition.org/laboreal/6330

Este documento foi criado de forma automática no dia 15 setembro 2020.

\section{(c) (†) (8)}

Laboreal está licenciado com uma Licença Creative Commons - Atribuição-NãoComercial 4.0 Internacional. 


\title{
Carga mental
}

\author{
Carga mental \\ Charge mentale \\ Mental workload
}

\section{Carlos Díaz Canepa}

Tradução : Marta Santos e Marianne Lacomblez

1 Como consequência do impacto sobre os conteúdos, formas e exigências do trabalho que resultaram da massificação das tecnologias de informação e comunicação, tem vindo a aumentar a preocupação entre os interessados pelas condições de trabalho e pela eficácia do desempenho humano em avaliar e gerir a carga mental de trabalho. No entanto, tal como o constatara Gillet (1987) há mais de vinte anos atrás, a definição e alcance do conceito de carga mental são ainda problemáticos. Isso reflete-se igualmente na grande diversidade de ferramentas que visam diferentes perspectivas e com conteúdos variados para a avaliação da carga mental de trabalho.

2 O conceito de Carga Mental remete, de um modo geral, para a pressão cognitiva e emocional resultante do confronto com as exigências associadas ao exercício do trabalho. No entanto, a história deste conceito tem seguido caminhos sinuosos, cruzando diversas fronteiras disciplinares. Nas suas origens o conceito de carga mental surge sob a influência de um conjunto de teorias sustentadas no desenvolvimento de modelos matemáticos elaborados no rescaldo da Segunda Guerra Mundial e que, em certa medida, procuravam simular as funções cognitivas humanas em sistemas técnicos. Entre elas, a Teoria da Informação criada por Shannon em 1948 nos Laboratórios Bell do Massachusetts Institute of Technology e posteriormente desenvolvida por Shannon e Weaver (1949), a Teoria Cibernética formalizada por Norbert Weiner (1948) e a Teoria Geral de Sistemas desenvolvida na mesma época por Ludwig von Bertalanffy (1950).

O conjunto destas teorias contribuiu, sem dúvida, para o desenvolvimento da psicologia cognitiva moderna, sendo utilizado como referências metafóricas para a descrição, explicação e avaliação das modalidades e capacidades de processamento da informação humana. Partindo desta perspetiva, George Miller (1956), por exemplo, demonstrou que 
a nossa capacidade de memória de curto prazo tinha limites mais ou menos definidos, e que se encontrava apenas em condições de processar simultaneamente $7 \pm 2$ dígitos por segundo. Complementarmente, os trabalhos de Broadbent (1958), centrados nos processos de atenção seletiva e memória de curto prazo, derivaram na formulação da tese denominada "Canal Único de Processamento de Informação", o que sugere que o conjunto de informação recebida através dos nossos distintos órgãos sensoriais, seria canalizado através de uma via única para o sistema nervoso central, onde seria processado integradamente. Para além da capacidade deste canal não seríamos capazes de processar sem gerar uma perda de informação, a menos que, conforme previsto pelo Chase e Simon (1973), as pessoas recorressem à integração e organização das informações em categorias compreensivas de nível superior de abstração. Tais categorias, chamadas de "chunk" (pedaços), constituiriam uma espécie de esquemas básicos a partir dos quais as pessoas, principalmente as mais experientes, reduziriam a complexidade dos problemas com que eram confrontadas e que teriam que resolver. Isto permitiria, eventualmente, uma maior capacidade de processamento de informação, já que, através dos "chunk", se libertariam porções da capacidade de processamento cognitivo. Um exemplo disto, é que para memorizar um número de telefone, os dígitos agrupam-se em grupos ou "chunks" de 3 e 2 dígitos; assim, o número 6784932, seria mais fácil de recordar como 678-49-32.

4 Assim, as pessoas teriam a possibilidade de redefinir a organização das unidades de informação processadas, capacidade que variaria em função da natureza da informação tratada bem como das competências de que poderiam dispor para fazer face às exigências envolvidas nas tarefas que devem realizar (Kantowitz, 1985).

5 Partindo desta perspetiva, o conceito de carga mental esteve, nas suas origens, fortemente ligado à ideia de capacidade limitada da memória de trabalho, unidade concebida como a instância de armazenamento e processamento transitório de informação durante as atividades de resolução de problemas. Para além disso, estava ligado à ideia da existência de modalidades particulares de filtro e seleção de informação requeridas para o desenvolvimento dessas operações. Como se pode constatar, estas primeiras abordagens do conceito foram significativamente marcadas pela analogia da atividade humana com as máquinas de processamento de informação, especialmente os computadores. Deste modo, produziu-se um paradoxo que teve um grande impacto na teoria psicológica: a metáfora que visava aproximar o funcionamento dos novos artefactos cibernéticos aos modos de funcionamento humano, é revertida para explicar o funcionamento humano a partir de modelos informacionais e cibernéticos (Bruner, 1990). Não há dúvida que tal metáfora, se bem que permitiu abrir um canal fecundo de colaboração entre a psicologia, as ciências da educação e as ciências da engenharia, é hoje considerada insuficiente para explicar a complexidade dos processos envolvidos na configuração da carga mental.

6 É precisamente a partir da perspetiva da ergonomia, que emerge a inquietação pela incidência de fatores contextuais sobre a carga mental, ao constatar-se a existência de desvios perturbadores entre o obtido em condições de laboratório e aqueles comportamentos identificados em condição real no momento de realização das análises e intervenções no terreno. Para esta perspetiva, uma primeira ambiguidade conceptual que importou definir foi a distinção entre carga de trabalho mental e carga mental de trabalho. A carga de trabalho mental diria respeito à carga de trabalho resultante do exercício de atividades cujas principais componentes interpelam a execução de 
processos mentais e emocionais resultantes, por exemplo, da atividade de interpretar e codificar sinais, relacionar elementos, diagnosticar e tomar decisões, etc. Tal conceptualização tendeu a concentrar as avaliações em tarefas apelidadas de "intelectuais" e de controlo de processos, enquanto o conceito de carga mental de trabalho apontaria, de um modo mais amplo, para a pressão mental resultante do confronto com as diversas exigências associadas ao exercício de uma determinada atividade, tenha ela um enfoque físico ou mental. Outra distinção relevante a considerar diz respeito ao conceito de fadiga mental. Sperandio (1984) assinala que existiria uma certa tendência para confundir estes conceitos associados aos efeitos resultantes da realização do trabalho, precisando que a fadiga poderia ser assimilada a uma simples extensão da carga de trabalho sentida durante a tarefa. A carga mental de trabalho seria, então, um fenómeno que apenas aconteceria durante o desempenho da atividade como resultado do grau de mobilização dos recursos e capacidades das pessoas, enquanto que a fadiga responderia de modo imbricado ao confronto com as exigências físicas e sensoriais associadas ao exercício da atividade e a transcenderia, tendo consequências na disponibilidade dos recursos e capacidades requeridas para o desempenho desta, afetando também, em termos gerais, a qualidade de vida das pessoas. Concordando com ele, González, Moreno e Garrosa (2005) assinalam que a exposição a situações que podem gerar sobrecarga ou infracarga mental podem efetivamente ter efeitos cumulativos sobre o indivíduo, dando lugar a estados de fadiga.

7 É importante destacar que uma das caraterísticas fundamentais do conceito de carga mental é a sua natureza relativa. A literatura que se refere à carga mental tende a vincar em como não existiria uma relação mecânica entre condições objetivas de trabalho e carga mental, pois tal como o aponta Theureau (2001), as pessoas tenderiam a redefinir as tarefas e as exigências derivadas delas com base nas situações concretas em que se realizam, nas suas próprias caraterísticas e objetivos pessoais. Assim, por exemplo, para dar conta de uma mesma tarefa, a carga mental não seria a mesma para uma pessoa jovem, competente, de boa saúde, experimentada, motivada e inscrita numa rede socio-organizacional consolidada ou para uma pessoa de idade avançada, pouco competente, que apresente problemas de saúde, com escassa experiência, desmotivada e isolada social e organizacionalmente. Dito de outro modo, a carga de trabalho, resultante do desempenho de uma tarefa, seria função dos recursos que cada pessoa dispõe para a poder enfrentar (Gillet 1987 ; Leplat, 1997 ; Leplat 2004 ; Sperandio 1984 ; O’Donnell \& Eggemeier 1986).

8 Seguindo os argumentos expostos anteriormente, é possível concluir provisoriamente que a relação entre exigências do trabalho e carga mental não seria de natureza unívoca em que esta resultaria da simples pressão exercida pelas exigências formalmente reconhecidas do trabalho sobre as pessoas (por exemplo, volume, dispersão, ritmo, contexto, duração, etc. da tarefa). Dito de modo sintético, a carga mental derivaria de uma interação dinâmica que se produziria entre as caraterísticas das pessoas, a natureza e forma de atualização da exigência e o significado que as pessoas atribuem às exigências no decurso da sua atividade. Tal dinâmica determinaria em grande medida, o modo de realização da atividade efetiva das pessoas, sendo neste processo, no qual as pessoas assumem um papel de protagonismo, que se configuraria a carga mental resultante.

Os métodos utilizados para a avaliação da carga mental são de ordem variada, tendo em comum o seu carácter de se basearem em indicadores indiretos. Assim, é possível 
encontrar uma grande variedade de questionários baseados no levantamento das exigências e/ou das perceções dos que estão envolvidos nas atividades avaliadas, tal como o método desenvolvido pela ANACT (Piotet y Mabile 1984), o método NASA-TLX, desenvolvido pela Aerospace Human Factors Research Division da NASA, no seu centro de investigação de Ames (Hart y Stavenland, 1988), a escala de Carga Global desenvolvida por Vidulich y Tsang (1987), o método Subjective Workload Assessment Technique (SWAT), desenvolvido por Reid \& Nygred (1988), o método Ergonomics Workplace Analysis (EWA), desenvolvido pelo Instituto Finlandês de Saúde Ocupacional (Dalmau \& Nogareda, 1998), etc. Do mesmo modo, utilizam-se interessantes técnicas baseadas no estudo das variações dos modos operatórios, assim como os métodos apoiados na monitorização de indicadores fisiológicos (Sperandio, 1984).

\section{BIBLIOGRAFIA}

Bertalanffy, L.V. (1950). An outline of general system theory. British Journal for Phylosophy of Science. 139-164.

Broadbent , D. (1958). Perception and communication. London: Pergamon Press.

Bruner, J. (1990). Acts of meaning. USA : Harvard University Press.

Dalmau, I, \& Nogareda C. (1998). NTP 451 : Evaluación de las condiciones de trabajo : métodos generales. Ministerio del Trabajo y Asuntos Sociales. España. Instituto Nacional de Seguridad e Higiene en el Trabajo.

Gillet, B. (1987). La psychologie en ergonomie. Traité de psychologie ergonomique. Issy-lesMoulineaux : EAP.

González, J. L., Moreno, B., \& Garrosa, E. (2005). Carga mental y fatiga laboral. Madrid: Piramide.

Hart, S. G., \& Stavenland, L.E. (1988). Development of NASA-TLX (Task Load Index): Results of empirical and theoretical research. In P. A. Hancock \& N. Meshkati, Human Mental Workload, Elsevier Science Publishers. (139-183).

Kantowitz, B.H. (1985). Stages and channels in human information processing: A limited review and analysis of theory and methodology. Journal of Mathematical Psychology, 29. 135-174.

Leplat, J. (1997). Regards sur l'activité en situation de travail. Contribution à la psychologie ergonomique. Paris : PUF-Le travail Humain.

Leplat, J. (2004). L'analyse psychologique du travail. Revue Européene de Psychologie Appliquée, 54, 101-108.

Miller, G. (1956). The magical number seven, plus or minus two: some limits on our capacity for processing information. Psychological Review. 63, 81-97.

O’Donnell, R. D, \& Eggemeier, F.T. (1986.) Workload assessment methodology. In K. Boff, L. Kaufman \& J. Thomas (Eds.). Handbook of perception and human performance, vol. II. New York: Wiley Interscience. 
Piotet, F., \& Mabile, J. (1984). Conditions de travail, mode d'emploi. (col. Outils et methods). A.N.A.C.T.: Montrouge.

Reid, G., \& Nygren, T. (1988). The Subjective Workload Assessment Technique: A scaling procedure for measuring mental workload., In P. A. Hancock \& N. Meshkati, Human Mental Workload, Elsevier Science Publishers (185-218).

Shannon, C. E. (1948). A mathematical theory of communication. The Bell System Technical Journal. 27, 379-423, 623-656.

Shannon, C.E., \& Weaver, W. (1949). A Mathematical model of communication. Urbana, IL : University of Illinois Press.

Sperandio, J. C. (1980). La psychologie en ergonomie. Paris : PUF.

Sperandio, J. C. (1984). L'ergonomie du travail mentale. Paris : Masson.

Theureau, J. (2001). La notion de charge mentale est-elle soluble dans l'analyse du travail et la conception ergonomiques. Conférence introductive aux Journées ct'ing/Ergonomia, Cassis.

Vidulich, M.A, \& Tsang, P. S. (1987). Absolute magnitude estimation and relative judgement approaches to subjective workload assessment. In Proceedings of the Human Factors Society 31st Anual Meeting, 1057- 1061. Santa Monica, CA: Human Factors Society.

Weiner, N. (1948). Cybernetics; or control and communication in the animal and the machine. New York : Wiley.

ÍNDICE

Temas: O Dicionário

\section{AUTORES}

\section{CARLOS DÍAZ CANEPA}

Departamento de Psicologia, Facultad de Ciencias Sociales de la Universidad de Chile, Av. Capitán Ignacio Carrera Pinto №1045, Ñuñoa, Santiago de Chile carldiaz@uchile.cl 